\title{
The Development History of Chinese TV Audience Ratings and Its Critical Thinking
}

\author{
Qiyun Chang \\ Institute of Communication Studies, Communication University of China, Beijing, China \\ Email: 26703577@qq.com
}

Received 9 April 2014; revised 11 May 2014; accepted 20 May 2014

Copyright @ 2014 by author and Scientific Research Publishing Inc.

This work is licensed under the Creative Commons Attribution International License (CC BY). http://creativecommons.org/licenses/by/4.0/

(c) () Open Access

\begin{abstract}
Along with Chinese economic system transition from a planned economy to market economy, Chinese television audience survey also implements the changes from the audience's letters, calls, collective and individual interviews in the 1980s, to the TV audience ratings of the 1990s. But the TV audience ratings purely take the AD share and economic interests as the guidance, under the globalization era background, not only can greatly reduce the TV programs quality, but also eventually lead to the crisis of Chinese traditional culture.
\end{abstract}

\section{Keywords}

TV Audience Ratings, Development History, Positive and Negative Effects, Culture Crisis, China

\section{Introduction}

The so-called ratings, according to the GGTAM (the Global Guidelines for Television on Measurement), refer to the average percentage of the population who are watching TV among all TV penetration population, in a certain period of time, according to the estimated amount by the sample survey. TV penetration population refers to the population with TV (also referred to all the population in the survey) (Zheng, 2002: 3). Through the ratings we can obtain samples, for example, sample family or individual whether to watch TV, watch what channel and what program in each period of continuous observation. In addition to these, there is other record information, including association with ratings or the resulting derivative of other indicators, such as market share, total audience composition, CPP, arrival rate, fan loyalty, etc. Telephone interview method, writing diary method and method of measuring instrument, are composed of the three main methods of data collection of television ratings.

With the development of television industry and market competition intensifying, TV ratings, now have become the blade of a knife dharma Chris on the top of the heads of television personalities. Depending on the TV 
ratings, TV managers determine which one will be eliminated; TV practitioners can get more bonuses in which month; TV producers decide to adopt which kind of innovation decision. All of these are due to the advertiser, according to the TV ratings, to determine whether to advertise or to spend how much advertising is.

TV ratings are an imported method from the west, then, how to develop step by step in China, what are the causes of its rapid development, what are the positive or negative influences, how to think the cultural crisis through the impacts of TV ratings, and so on. These questions constitute the article's research emphasis. Research method is mainly qualitative analysis.

The purpose and significance of this paper lie mainly in: 1) revealing the rapid development history, the market environments and policy factors of the TV audiences ratings research in China; 2) analysis of the positive and negative influence of the TV audiences ratings research in moden China; 3) by revealing the surface phenomena of relying solely on the audience TV ratings, analyzing the current cultural crisis behind the phenomena in the realistic social context of China.

\section{The Development History of Chinese Television Audience Ratings}

Throughout more than 50 years development history of China's TV, we can found that the strict audience research in most of the time is blank. So-called audience research in the past, were mainly dealing with audience's letter, call, and audiences meeting or individual interview, these methods mostly stay in microscopic and shallow level, more fragmented and simple, which is because on the one hand, at that time, people had not yet found one more scientific way of audience research, on the other hand, at that time Chinese media market was protected by the planned economy system, with particular emphasis on the media's "mouthpiece" function, combining with the shortage of TV channels which caused "seller's market" dominated by communicators , the audience were only the publicity objects to TV media, at that time almost no attention to the publicity effect, because if you searched "Chinese radio and TV yearbook", you may find that in the previous articles in the 1980s, not an article was to discuss the audience research.

But since reform and opening up policy in 1978, especially after "level 4 do TV policy" in 1983 (that is to say, from the national TV, to provincial TV , to city TV, to county TV), during a few short years, the number of television stations in mainland China sharply increased, by 1990 the TV coverage population has reached 79.4\%, a 20\% increase over the 1983 (Liu et al., 1998: 10), including the size , structure and distribution of the audience. While no total market economic system, but the development of commodity economy, has made more and more market competition, programs quantity and air time increased significantly, so these improved audience's choice space, the ratings demand tended to diversified characteristics. These changes are already beyond the scope of the traditional experience, the new situation requires the TV producers must understand the audience's interest, hobbies and expectations. In 1986 and 1987, the central television station successively presided over the national audience research in 28 cities and the first national urban and rural audience survey, two audience research in China caused a strong reaction. Almost as much as to say, the two audience survey officially opened the prelude of China's large audience research.

Since the middle and late of 1990's, China's television ratings research began to rapid development, not only means start from the diary card to the staff measurement instrument and survey network is also fast expanding. In 1996, the world leader in the field of TV ratings-AC Nielsen Media research company whose headquarter lies in New York, entered into China and set up in Shanghai, and then firstly launch a kind of television ratings, that is a method of personnel measuring instrument. In 1997 CCTV survey center (CVSC, or now of the CCTV market research firm, CTR) and French CSM group (Sofres, namely now Taylar Nelson Sofres, TNS) cooperated and established CSM media research Co. LTD by the holding of CCTV survey information center. In 1999, the total turnover of TV ratings business in mainland Chinese were nearly one hundred and twenty million yuan, and CSM accounted for about $85 \%$ of the share. Compared with the turnover of only a few million yuan, this is undoubtedly a huge leap. By the end of 2000, China had developed the world's largest audience ratings research network, the samples are more than 22,000 households, 24-hour uninterrupted monitoring the viewers of 700 main TV channel (Liu, 2006: 233-243). Television ratings research also gradually formed a relatively independent emerging industry. Until now, China has more than about 100 ratings agencies.

At the same time, TV ratings index in the adjustment of program system and program schedule between the buyer and the seller also began to play an increasingly important role. When all television stations decided which program would be cut off, they mostly relied on the TV ratings. Those canceled programs, in other words, 
were basically because of its very low TV ratings. In fact, many television stations have the ratings as a relatively objective quantitative indicator, used for internal management, staff rewards and punishments and channel management, as far as possible to avoid the interference from human factors. In program marketing, the phenomenon, that is according to the TV ratings is high or low to decide program price, also begins popularity. As for in the advertising business, the role of TV ratings and its series index are all more important.

\section{The Reasons of Rapid Development of Chinese TV Audience Ratings}

The author thinks that, in recent years the rapid development of TV ratings investigation, the main reasons are: First, more and more intense domestic market competition and the entry of foreign media, in turn, produced a large number of market demands, in order to win in the competition, each TV station must through television ratings and its series index understand and found the audience's hobbies, interesting, flavor and so on, so that they can target to meet the demand of the audience.

Second, because of the government adopted the so-called "weaning policy", to reduce or even cancel the financial aid of most of the institutions, including television stations, which makes TV industry, the high input, high consumption, heavy equipment industry is fully thrown into the market, strives for the survival by market, traditional administrative management model and vertical control functions cannot adapt to market economy model, and market economy model inevitably needs its corresponding adjustment mechanism, TV ratings undoubtedly is the main representative of this mechanism.

Third, in the middle and late 1990s, most of the top 10 advertising companies in mainland China are the joint venture company, annual turnover accounted for one third of the total mainland TV advertising and almost mastered the lifeblood of Chinese television. Without exception, these companies rely on the TV ratings as the basis of advertising media, their exemplary role caused the domestic advertising companies and advertisers to emulate. During this period, the transaction was controlled from the seller's market to buyer's market, the survival pressure force most TV stations to emphasize and pursuit the high TV ratings, in order to increase its weight when dialoguing with advertising company. In the face of foreign media, the domestic media in order to enhance their strength, to resist external shocks, must be familiar with and consciously to integrate with the world. Therefore, the TV rating investigation, the foreign import method, can be developing rapidly in China, which is naturally easy to understand.

\section{The Impacts on Chinese TV Show from Television Audience Ratings}

Television audience ratings for TV show itself and television advertising has a significant effect: First, the TV ratings ha positive impact on the television program.

TV ratings index as an objective indicator of quantitative, to some extent, it reflects viewers whether concern for the program. That is to say, TV ratings reflect the percentage of a population, by this percentage can clearly know how many people to watch TV. Therefore, the introduction of television ratings index undoubtedly promote the competition between TV institutions, making television organizations pay more attention to meet the needs of audience, gradually get rid of the past "communicators as the center" model, began to focus on program communication effect. In this process, TV ratings contributed to the rapid development of "civil" wave in China's TV show, at the same time, television's populist wave then further stimulate greater masses of audience interest and viewing requirements, therefore, the combination of market demand and supply makes the TV programs are becoming more and more close to the market, and achieve the successful transition of TV industry from the planned economy system to market economic system .This populist wave, make TV news programs not only began to tell "the civilian's story”, such as “1860 news eyes” from Jiangsu TV station; TV entertainment programs, such as "happy girl” from Hunan TV station, also started to "shape grass-roots star”, and this trend also gradually broke the borders between news programs and arts programs, to permeate a variety of types such as the TV movie, TV series, sports programs, and so on.

The constant appearance of entertainment talent shows, the people's livelihood news programs and dialect columns shows are the symbol of the will and attitude that the Chinese television down the "communicators as the center" shrines and return to "serve the people”. TV programs take the TV audience ratings as an indicator, take the civil tendency as the creation principle, make TV content presented dversification trend, also make the TV technique more diversification, and promote the positive development of China's TV programs.

Second, the negative effects of TV ratings for on TV show. 
1) The one-sided emphasis on improving TV ratings, inevitably lead program to pursuit the popularization rather than specialization, and the result of the popularization led to more and more identical programs, and eventually led to waste of resources and led to viciously compete each other. That is to say, as the new media and foreign media swarmed into the mainland market, TV market competition will become increasingly cutthroat. Chinese Television stations for their own survival and development, create some of the novel and unique program form, and have achieved considerable viewing returns, it was understandable for media. However, some media blindly follow the suit, one-sided pursuit of TV ratings and lower program grade, relax advertising audit requirements, abuse to broadcast some bad programs even false advertisement, even seriously deviated from the mass media culture and aesthetic function, damage authority and credibility of the TV media.

2) TV programs homogeneity, caused the waste of resources and reduced the creativity of TV media, which is the most serious weakness, the "clone” phenomenon, in China's TV field. One is the "clone" of foreign programming, such as "the wall is coming”, a kind of CCTV entertainment program; Second is the "clone” phenomenon among the domestic mainland media, there are the most obvious in the entertainment program such as "choosing grassroots star" and dating shows, the content and form of the two types of programs are almost the same. This is, on the one hand, due to the special management system of the mainland TV institutions, the competition between TV stations is not very clear, on the other hand also reflects their very weak consciousness of the original opinion and of intellectual property. In addition, some TV programs are positioning on blindly catering to the tastes of the public, locating the audience in the most simple funny entertainment level, which makes the program only "in chaos", lost the real aesthetic value, this is just the direct embodiment of the business profits.

3) As a group, the TV audience have a herd mentality. If one-sided pursuit of TV ratings, media agenda setting combined with audience herd mentality, which can produce powerful sway force, it is easy to mislead the audience. If they show too much flatter for those seemingly popular but vulgarity programs, under the phantom of the high TV ratings, viewers tend to blindly believe it, this will cause more negative effects.

Third, the influence on TV advertising in China With the development of China's television industry marketization, and industrialization, in order to survive itself, each TV station began to hot pursue the TV ratings, and then win more and more advertising income via high TV ratings. Under this situation, in specific operations, for example, the choreography of TV programs is naturally inclined to advertising, instead neglect the television audience, and respect more and more advertising income as its power, rather than the quality of the programs,

The pursuit and dependence on advertising has brought a lot of bad consequences, many news media in order to win more share of the advertising, broadcast some bad ads which contain gender discrimination, the feudal superstition and hedonism, money worship and consumerism, and even illegal advertising, so a plenty of advertising encroached on a lot of showing time, so that the audience banter this phenomenon for "not watch shows, watch advertisements”.

\section{The Cultural Crisis behind the TV Ratings}

In general, the development of China's television ratings research, is also a TV ratings are controversial in China. In the late $1990 \mathrm{~s}$ and early 21st century, the controversy of the TV ratings is mainly whether the investigation data are scientific and accuracy. 2003 years later, because television vulgarization has become increasingly rampant and gradually become a common concerns for TV industry, TV ratings are considered as more vulgar wind and lower in quality, so that constantly suffer criticism. For example, Xiaofeng Li, the head of Chongqing TV station, directly put forward, "ratings is the root of all evil".

There is an old saying in China, "turnip or cabbage, according to his taste”. Just as people can choose according to his taste, different brands of TV, for different types of TV programs, inevitably because of the factors such as different knowledge background and personality preferences, age difference, and so on, there are huge differences. In this sense, there does not exist inevitable direct connection between the quality of TV shows itself and the number of the audience. On the other hand, low TV ratings does not mean poor quality of the art of the show. Therefore, the author believed that the so-called ratings itself, at best, is a kind of tool that can provide us the reference data about how many people be fond of a television show, sex ratio, background conditions, and so on, but not a tool by judging the program quality.

But, under the action of commercial interests, the emergence of the ratings is fundamentally the inevitable result of TV market operation under the system of commodity economy, is the TV market trying to produce "dis- 
course hegemony" in order to achieve economic benefit maximization (Zhang, 2009: 38-40). Because having high ratings equals wining the right to life in the fierce market competition, so, in order to improve the ratings, many TV programs constantly revised, tried to use the entertainment, even the vulgarity and philistinism, to attract more audience, make artificially manufacture, promote TV ratings openly instead of objective data itself. As a result, some value system and cultural concept originated in western consumer society have been more and more transplanted into the contemporary Chinese society, so that many consumers gradually faced with this problem: they should surrender to the western entertainment culture or abide by the Chinese traditional humanistic ethics?

Take the TV Series "ugly Wudi", the high rating program as an example, this TV Series adapted from the US version of "ugly Betty", the hit TV series in the United States which swept many of the year awards. Its content was full of American-style humor, the TV play in production mode and the audience's interaction realized the connection with the developed countries in Europe and American. However, when we revel in the high TV ratings programs, whether we should rationally reflect whether the American-style humor life is subtly instead of our traditional life value? And whether the American-humor life, which we aspire really has a higher value than our national life?

On the other hand, more terrible cultural crisis is is that we are sure that we voluntarily accept or agree with the western "cultural center doctrine" position which is more terrible on invasion of western culture on Chinese culture. In other words, we unconsciously identified with the western culture, and regarded western culture as "advanced", "fashion", "superior" symbol, what is the most terrible cultural colonization. The concept of the western cultural center doctrine embodies in film culture industry, the most typical fact is the impact on the domestic industry of Hollywood movies. Along with the cultural colonization of the third world countries, like American Betty, the character of the humor in life, we have once confidence of traditional cultural center position which were gradually marginalized and exiled, we completely ignored the social landscape, let our brains filled with fantasy and longing for the American dream.

\section{Conclusion}

From 1990's up to now, the TV audience ratings research from the west has three stages including telephone interview method, writing diary method and method of measuring instrument; until now, the TV ratings have become the blade of a knife dharma Chris on the top of the heads of television personalities. Depending on these data, the ratings are high or low which determines more or less of the TV column's advertising profit, also decides up or down of the television practitioners' salary, even determines the retention or removal of TV programs.

The brutal market competition promotes the rapid development of Chinese TV industry, also brought the program homogenization, vulgar, consumerism prevails, the value of traditional culture rupture, appeared the serious crisis of culture, therefore, was that "ratings are the root of all evil".

On one hand, the audience rating of TV program has promoted the rapid development of Chinese TV industry through the brutal market competition, on the other hand, also brought the program homogenization, vulgar, and the ideology of consumerism prevails, the value of traditional culture rupture, which appeared the serious crisis of culture, therefore, some TV producer and scholars directly put forward, "the audience rating of TV program is the root of all evil".

Television ratings, therefore, are the product of commercial market; to some extent, they have some kind of "original sin" of the commercial society. Just as Bourdieu, the French cultural criticism scholar, once pointed out that the appearance of television ratings forms an economic field which is still monitoring television programs, and the TV ratings also become a secret god; it ruled the circle (Shi, 2003).

But at present, the attention focused on television ratings is criticism of the negative phenomenon; the constructive suggestions, in fact, are more important. The undeniable fact is that, in market-oriented Chinese TV industry, we can't completely get rid of the ratings, therefore, how to make use of the positive role and curb the shortcomings of the TV rating are the feasible direction of the next step.

\section{References}

Liu, J. M. et al. (1998). The Analysis Report of the National Television Audience Sample Survey in 1997//Luoming etc. The Report of Chinese Television Audience. Beijing: Social Sciences and Academic Press, 10. 
Liu, Y. N. (2006). The Analysis of Television Ratings: Investigation, Analysis and Application. Beijing: The Communication University of China Publishing House, 233-243.

Shi, T. Y. (2003). TV Criticism Theory. Beijing: China Broadcasting and Television Press.

Zhang, X. L. (2009). The Cultural Crisis in the Ratings Era-To the Rating Phenomenon of the "Ugly Wudi" as a Case. Journal of Advertising Observatory (Comprehensive), 38-40.

Zheng, W. D. (2002). Ratings and Ratings Investigation/Focus on Ratings. Beijing: Beijing Broadcasting Institute Press, 3. 